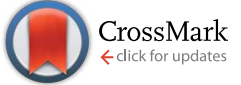

Cite this: J. Mater. Chem. A, 2016, 4, 18002

Received 31st August 2016

Accepted 13th October 2016

DOI: $10.1039 / \mathrm{c} 6 \mathrm{ta0} 521 \mathrm{e}$

www.rsc.org/MaterialsA

\section{Macroporous monolithic Magnéli-phase titanium suboxides as anode material for effective bioelectricity generation in microbial fuel cells $\uparrow$}

\author{
Ming Ma, ${ }^{a}$ Shijie You, ${ }^{\star a}$ Guoshuai Liu, ${ }^{a}$ Jiuhui $Q u^{b}$ and Nanqi Ren ${ }^{a}$ \\ A macroporous monolithic ceramic anode material based on Magnéli-phase titanium suboxides, fabricated \\ by a facile method, is able to effectively generate bioelectricity in microbial fuel cells (MFCs). Owing to their \\ highly active surface area and efficient extracellular electron transfer from electricigens to the anode, MFCs \\ can achieve a peak biocurrent time of $37 \mathrm{~h}$ with a maximum power density of $1541 \pm 18 \mathrm{~mW} \mathrm{~m}^{-2}$.
}

Microbial fuel cells (MFCs) are able to convert chemical energy from organic substances into electricity by an exoelectrogenic biofilm grown on the anode, which offers a sustainable technology to recover energy from organic waste. ${ }^{1}$ In MFCs, the electrons stored in organic matter are first released during the microbial metabolism, followed by transfer to the anode through the extracellular electron transfer (EET) process. The EET can proceed via direct contact of $c$-type cytochromes on the bacterial outer membrane, ${ }^{2}$ long-distance transport by conductive bacterial pili (i.e. nanowires), ${ }^{3}$ and indirect mediated transfer via electron shuttles. ${ }^{4}$ As EET constitutes one of the most significant steps that limit the magnitude of power produced in an MFC, there is an increasing interest in developing effective anode materials and structures for electroactive biofilm attachment and power generation.

Much effort has been invested in exploring anode materials for the enrichment of exoelectrogenic bacteria. These anode materials should have an open-cell macro- and mesoscale porous structure to allow a multi-dimensional colonization and to increase the anolyte-biofilm-anode interfacial area for mass transfer and electron transport. ${ }^{5}$ For materials containing $2 \mathrm{D}$ and $3 \mathrm{D}$ microscale pores, the rapid microbial growth will clog the pores and hinder the inner colonization and substrate diffusion. ${ }^{6}$ Moreover, the long-term mechanical strength and stability of conventional carbon-based electrodes may be another concern as a consequence of interfacial corrosion and oxidation of the anode material. ${ }^{7}$ Based on these considerations, it will be highly desirable to develop macroporous, highly conductive and chemically stable electrode materials for

${ }^{a}$ State Key Laboratory of Urban Water Resource and Environment, Harbin Institute of Technology, 73 Huanghe Road, Nangang District, Harbin 150090, China. E-mail: sjyou@hit.edu.cn

${ }^{b}$ State Key Laboratory of Environmental Aquatic Chemistry, Research Centre for EcoEnvironmental Sciences, Chinese Academy of Sciences, Beijing 100085, China

$\dagger$ Electronic supplementary information (ESI) available: Experimental section, Fig. S1, and Table S1. See DOI: 10.1039/c6ta07521e efficient attachment of electrochemically active microorganisms and viable electricity generation in MFC systems.

Titanium dioxide $\left(\mathrm{TiO}_{2}\right)$ is a well-known semi-conductor, which has been widely used in photocatalytic reactions. Interestingly, the electronic properties of $\mathrm{TiO}_{2}$ can be drastically transformed by establishing oxygen deficiencies within the crystalline lattice, affording what is known as Magnéli-phase titanium suboxides, with a generic formula of $\mathrm{Ti}_{x} \mathrm{O}_{2 x-1}(4 \leq x \leq$ 10). ${ }^{8}$ Magnéli-phase titanium suboxides have a crystal structure with an oxygen deficiency for every $x$ th layer, resulting in shear planes where $2 \mathrm{D}$ chains of octahedra become face-sharing to accommodate the deficiency in oxygen. This unique structure leads to a combination of outstanding electrical conductivity similar to that of metals and a great corrosion resistance close to that of ceramic materials. ${ }^{9}$ For example, $\mathrm{Ti}_{4} \mathrm{O}_{7}(x=4$, under trade name Ebonex®, Atraverda Ltd, U.K.) exhibits a great conductivity of $\sim 1050 \mathrm{~S} \mathrm{~cm}^{-1}$, which is even higher than that of graphitic carbon $\left(\sim 727 \mathrm{~S} \mathrm{~cm}^{-1}\right) \cdot{ }^{10}$ In addition, $\mathrm{Ti}_{4} \mathrm{O}_{7}$ can also exhibit higher oxygen evolution potential $(+2.6 \mathrm{~V} v s$. standard hydrogen electrode, SHE) than BDD. ${ }^{11,12}$ These properties make $\mathrm{Ti}_{4} \mathrm{O}_{7}$ suitable for many electrochemical applications, such as cathodic protection, ${ }^{13}$ bipolar battery, ${ }^{14}$ water splitting, ${ }^{15}$ as well as water treatment. ${ }^{16-18}$

Herein, the macroporous monolithic Magnéli-phase titanium suboxides (MM-TiSO) were prepared by annealing $\mathrm{TiO}_{2}$ in hydrogen and then applying the hot-press method. The MMTiSO showed good biocompatibility towards exoelectrogens, highly-ordered macroscopic pores (with a pore size of $0.5-2$ $\mathrm{mm})$ for substrate transfer, sufficiently thick skeletons for bacterial viability, maximized electrical conductivity $(0.38 \Omega$ $\mathrm{cm}^{-1}$ ), and long-term durability compared to traditional carbon-based materials.

As shown in Fig. 1a, the Magnéli-phase titanium suboxides are successfully synthesized by ventilation with $\mathrm{H}_{2}$ for $4 \mathrm{~h}$ at $1050{ }^{\circ} \mathrm{C}$. As the reaction proceeded, and the oxygen vacancies were generated, the white stoichiometric $\mathrm{TiO}_{2}$ powder was 


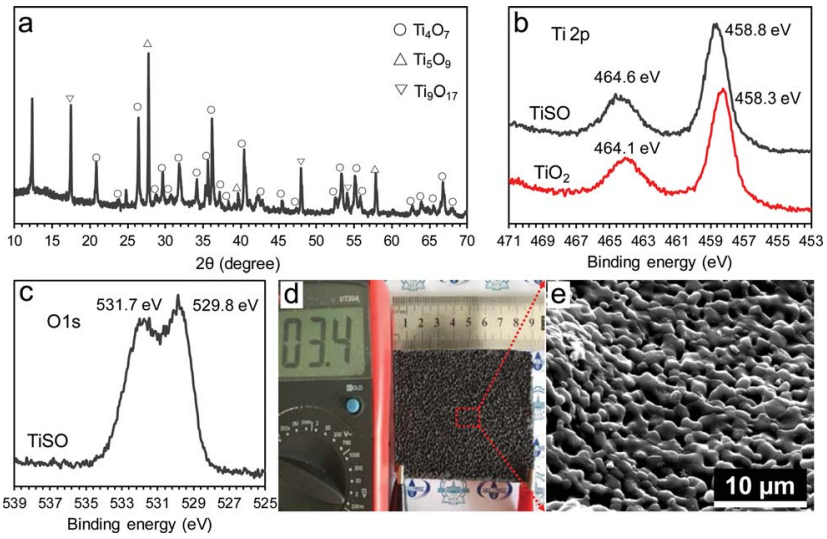

Fig. 1 (a) XRD pattern, XPS spectra of TiSO (b) $\mathrm{Ti} 2 \mathrm{p}$ for $\mathrm{TiO}_{2}$ and titanium suboxides (TiSO), (c) O1s of TiSO, and (d) optical images of MM-TiSO, and (e) SEM images.

gradually reduced to blue-black suboxide material. Three main crystalline phases $\left(\mathrm{Ti}_{4} \mathrm{O}_{7}, \mathrm{Ti}_{5} \mathrm{O}_{9}\right.$, and $\left.\mathrm{Ti}_{9} \mathrm{O}_{17}\right)$ can be identified from the characteristic diffraction peaks. Although $\mathrm{Ti}_{4} \mathrm{O}_{7}$ is the most conductive, to date, it appears technologically difficult to synthesize a pure phase of a titanium suboxide due to the different crystals forming in a very narrow range of temperatures $\left(1270-1340{ }^{\circ} \mathrm{C}\right),{ }^{14}$ which makes it quite difficult to precisely control the synthesis process in practice. ${ }^{19-25}$ The difference in these phases is the conductivity, and both $\mathrm{Ti}_{4} \mathrm{O}_{7}$ and $\mathrm{Ti}_{5} \mathrm{O}_{9}$ have a conductivity greater than $900 \mathrm{~S} \mathrm{~cm}^{-1},{ }^{26}$ which is even higher than that of graphite $\left(727 \mathrm{~S} \mathrm{~cm}^{-1}\right)$. Hence, there is a slight difference in the contribution of $\mathrm{Ti}_{4} \mathrm{O}_{7}$ and $\mathrm{Ti}_{5} \mathrm{O}_{9}$ in terms of their interaction with electrochemically active microorganisms except that the conductivity of the mixed phase is lower than that of pure-phase $\mathrm{Ti}_{4} \mathrm{O}_{7}$. As shown from the XPS spectra in Fig. $1 \mathrm{~b}$ and c, the Ti2 $\mathrm{p}_{3 / 2}$ and $2 \mathrm{p}_{1 / 2}$ characteristic peaks could be observed for $\mathrm{TiO}_{2}$ at a binding energy (BE) of $458.3 \mathrm{eV}$ and $464.1 \mathrm{eV}$, respectively, which was consistent with data reported in previous studies. ${ }^{27}$ The corresponding BE for titanium suboxides (TiSO) shifted $0.5 \mathrm{eV}$ towards higher values due to the decrease in the surrounding electron density when $\mathrm{Ti}^{4+}$ was reduced. ${ }^{28}$ Moreover, the O1s peaks at a BE of $529.8 \mathrm{eV}$ and $531.7 \mathrm{eV}$ should be ascribed to oxygen from physically absorbed oxygen and the Ti-O bond, respectively. ${ }^{29}$

The as-prepared Magnéli-phase titanium suboxide powders were then hot-pressed to afford a honeycomb-like macroporous monolithic scaffold with a large surface area, excellent electrical conductivity $\left(0.38 \Omega \mathrm{cm}^{-1}\right)$, and a macroscopic pore size ranging from 0.5 to $2 \mathrm{~mm}$ (Fig. 1d). The surface of the MM-TiSO skeleton exhibits a homogeneous macroporous structure with a pore size of $0.5-1 \mu \mathrm{m}$ and a smooth grain microstructure of about $2 \mu \mathrm{m}$, which is clearly visible (Fig. 1e). These large pores and thick skeletons $(0.8-1.5 \mathrm{~mm})$ are expected to allow a more efficient substrate transport and internal colonization of microsized electrochemically active microbes (of several microns) for exchanging electrons.

To investigate the bioelectrochemical performance of the as-prepared MM-TiSO electrode, it was examined as a working electrode (WE) in a three-electrode half-cell system equipped with a saturated calomel reference electrode (SCE) and a platinum counter electrode (CE). The mixed electricigens, collected from the effluent of a well working MFC reactor, were inoculated onto the MM-TiSO anode, posited at a potential of $0 \mathrm{~V} v s$. the SCE. As the reaction proceeded, the oxidative current was observed to increase gradually, indicating that the attached exoelectrogens were capable of proliferating and transferring electrons from the cells to the electrode. The polarized bioanode initially displayed a higher peak current of $2.47 \mathrm{~mA}$ up to $3.6 \mathrm{~h}$ after inoculation (Fig. 2a), which was approximately 11-fold as much as that of carbon cloth (CC) $(0.225 \mathrm{~mA})$, and then declined dramatically thereafter. Furthermore, the current output time for MM-TiSO (12 h) was twice that for CC (6 h). The considerable improvement in biocurrent generation suggested the enhancement of the EET process by MM-TiSO. To elucidate the enhanced interfacial interactions between the electroactive biofilm and the anode, the electron transfer resistance was quantified by electrochemical impedance spectroscopy (EIS). As shown in the Nyquist plots (Fig. 2b), the two types of anodes presented a similar ohmic resistance of about $15 \Omega$, further confirming a good conductivity of the as-prepared MM-TiSO, comparable to that of CC. However, following the formation of the biofilm, MM-TiSO showed a much lower charge transfer resistance $(39.68 \Omega)$ than CC $(129.73 \Omega)$. This clearly suggests the enhanced interfacial EET, primarily due to the increased interfacial area and pore structure of the MM-TiSO material, which facilitates the attachment of electroactive biofilms on the MM-TiSO anode.

To further investigate the bioelectroactivity of the exoelectrogenic biofilms formed on different anodes, turnover cyclic voltammetry (CV) tests were performed in fresh acetate media. Fig. 2c shows typical characteristic sigmoidal voltammogram profiles for the anodes, representing the activity of the exoelectrogens. ${ }^{30,31}$ For both electrodes, the oxidation current was
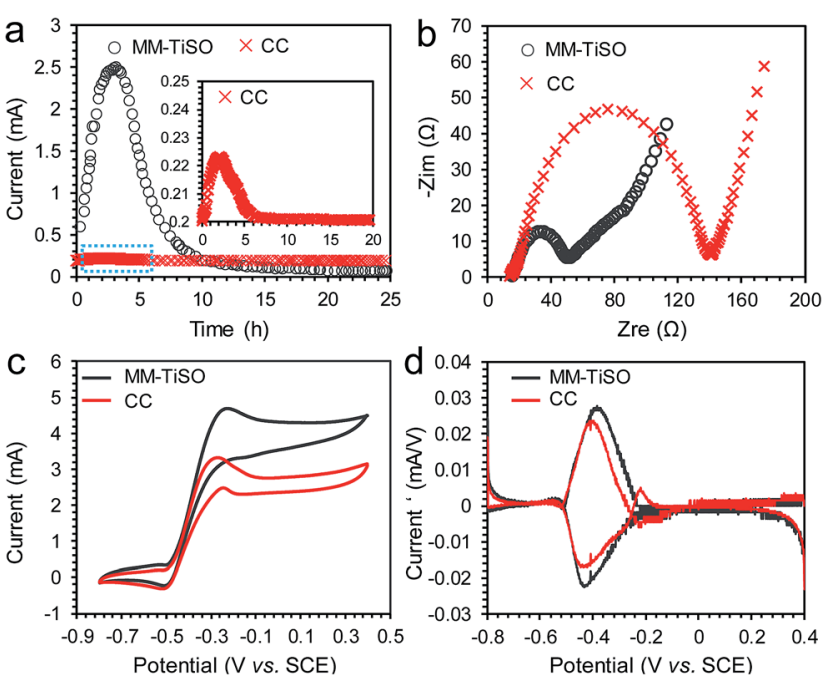

Fig. 2 (a) Production of current when using MM-TiSO and carbon cloth (CC) poised at $0 \mathrm{~V}$ vs. SCE, and magnification of CC in the inset. (b) Nyquist plots. (c) Turnover CV curves and (d) first-derivative of CV curves in acetate media ( $0.82 \mathrm{~g} \mathrm{~L}^{-1}$ concentration) for both anodes. 
produced at a voltage of $-0.49 \mathrm{~V}$, and then, with an increase in potential to $-0.24 \mathrm{~V}$, the current also increased, and subsequently remained stable within the high potential region, which was consistent with the polarization result. ${ }^{32}$ The electroactive biofilm formed on the MM-TisO anode produced higher bioelectroactivity with a stabilized current of $4.34 \mathrm{~mA}$, which was 1.56-fold as much as that of CC $(2.79 \mathrm{~mA})$. Notably, a higher capacitive current could also be achieved with the MM-TiSO anode, as a result of its unique 3D macroporous architecture. In particular, the first derivative of the $\mathrm{CV}$ curves revealed a redox pair centered at $-0.43 \mathrm{~V}$, which is in accordance with the redox potential of flavins in a pH-neutral medium (Fig. 2d). ${ }^{31}$ The biofilm accumulated on the MM-TiSO surface showed an increasing electroactivity over a broad voltage range from $-0.52 \mathrm{~V}$ to $-0.22 \mathrm{~V}$ compared to the biofilm on CC from $-0.52 \mathrm{~V}$ to $-0.25 \mathrm{~V}$, demonstrating that the bacteria on MM-TiSO expressed more EET-associated components so as to gain more energy for growth. ${ }^{33}$

The MM-TiSO was then studied as the anode of an MFC reactor for voltage and power generation during batch-fed operation. The MFCs were inoculated using a mixed culture in acetate $\left(0.82 \mathrm{~g} \mathrm{~L}^{-1}\right.$ concentration) at an external resistance $\left(R_{\mathrm{ex}}\right)$ of $1000 \Omega$. As revealed in Fig. 3a, a stable cell voltage of $0.581 \pm$ $0.02 \mathrm{~V}$ could be achieved for the MM-TiSO anode during a $420 \mathrm{~h}$ operation time, which was $16.7 \%$ higher than that achieved for CC $(0.498 \pm 0.035 \mathrm{~V})$. Notably, the enhanced voltage output of the MM-TiSO anode was also expressed by an increased cyclic operation time $(70 \mathrm{~h})$, which was nearly double that of the CC anode (38 h). To examine the dependence of power output on current density, polarization tests at the corresponding electrode potential were performed by a step-wise change of the external resistance, from 5000 to $50 \Omega$. Fig. 3 b shows that the MM-TiSO anode could produce electricity with a maximum power density of $1541 \pm 18 \mathrm{~mW} \mathrm{~m}^{-2}$ (at a current density of 4.08 $\pm 0.03 \mathrm{~A} \mathrm{~m}^{-2}$ and a higher open circuit voltage of $0.795 \mathrm{~V}$ ),
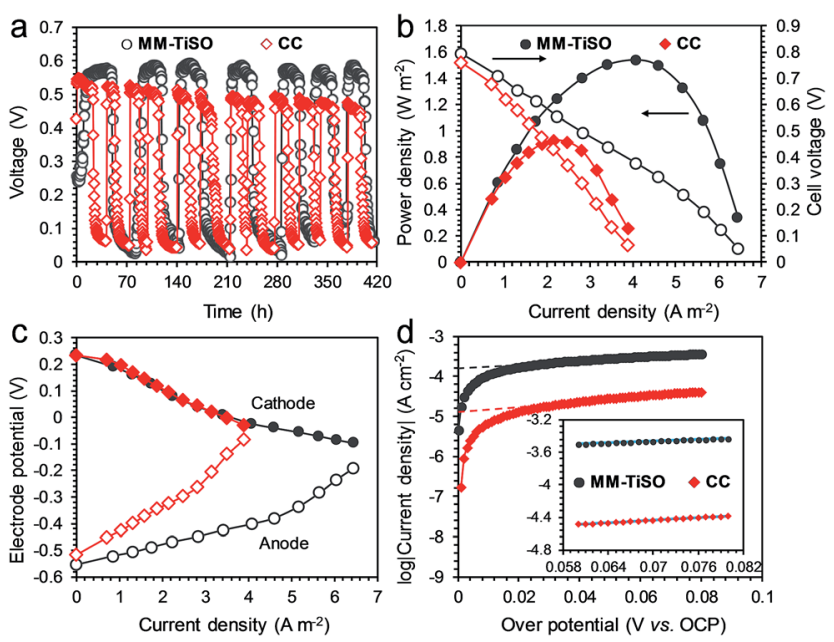

Fig. 3 (a) Voltage output time course plot, (b) power density vs. current density (c) electrode potential as a function of current density, (d) Tafel plots for both anodes. The inset figure is the linear fit for Tafel plots with an overpotential from $60 \mathrm{mV}$ to $80 \mathrm{mV}$. which was $65.34 \%$ higher than the power density achieved with the CC anode $\left(932 \pm 21 \mathrm{~mW} \mathrm{~m}^{-2}\right.$, at a current density of $2.16 \pm$ $0.05 \mathrm{~A} \mathrm{~m}^{-2}$ and an open circuit voltage of $\left.0.759 \mathrm{~V}\right)$. Such differences should be attributed to an enhanced anode performance rather than the cathode performance as the cathode potential varied slightly for both electrodes. As shown in Fig. 3c, during polarization, the potential observed for the MM-TiSO anode declined at a slower rate than for the CC anode, sustaining a much lower anode potential $(-0.403 \pm 0.005 \mathrm{~V} v$ s. SCE) than the CC anode $(-0.323 \pm 0.002 \mathrm{~V})$ upon reaching the maximum power density. This further confirmed the superiority of MM-TiSO as a bioanode material for energy recovery, since it was able to overcome a higher overpotential.

Next, the polarization behavior of the two electrodes based on the exchange current density $\left(j_{0}\right)$ was also calculated and compared according to Tafel plots. The $j_{0}$ value observed for MM-TiSO in a fresh anolyte $\left(1.58 \times 10^{-4} \mathrm{~A} \mathrm{~cm}^{-2}\right)$ was about 10.29-fold of that observed for CC $\left(0.14 \times 10^{-4} \mathrm{~A} \mathrm{~cm}^{-2}\right)$ (Fig. 3d), and this result was in good agreement with the maximum voltage and power output results. Moreover, for MM-TiSO, the slightly lower Tafel slope and larger $j_{0}$ value indicated a higher bioelectrocatalytic activity and EET efficiency. ${ }^{34}$ Moreover, it was found that the two electrodes had an almost identical Tafel slope at the fixed potential, which suggested similar interfacial reaction mechanisms over this range of potentials. ${ }^{35}$ Taken together, the MM-TiSO anode could achieve a superior EET kinetics and performance compared with the traditional CC anode or other materials used in MFCs, ${ }^{36-38}$ such as carbon-based nanomaterials, ${ }^{39,40}$ conductive polymers, ${ }^{41}$ transition metal oxides, ${ }^{42}$ and their hybrids (Table $\mathrm{S} 1 \dagger) .^{43}$

The non-turnover CV scans were also performed in depleted acetate medium until the current decreased to $0 \mathrm{~mA}$. As illustrated in Fig. 4a and b, the typical shape of voltammograms could be seen for the exoelectrogens, whose bioelectrochemical
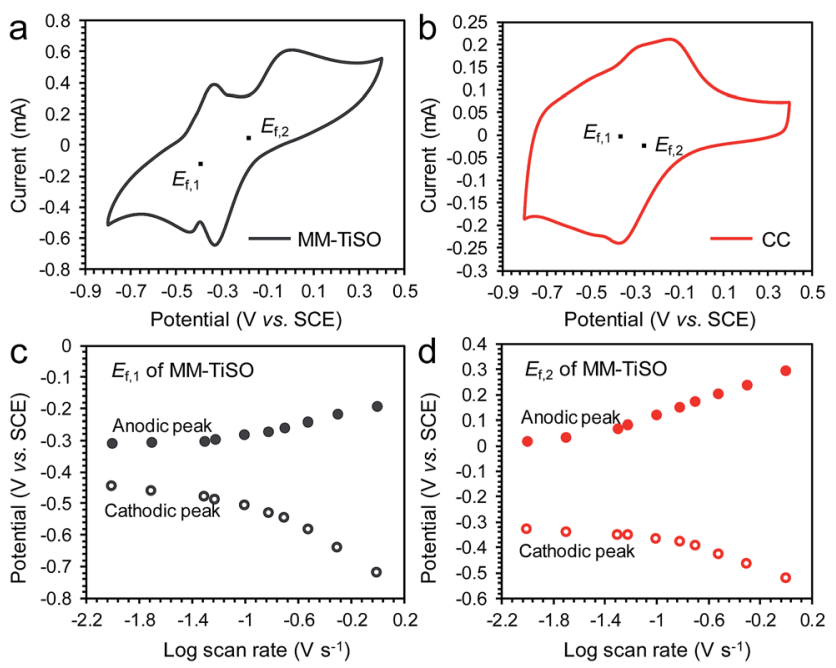

Fig. 4 Non-turnover CV curves recorded in depleted substrate media for different anodes ( $a$ and $b)$, and the influence of scan rate on redox peaks of (c) $E_{\mathrm{f}, 1}$ and (d) $E_{\mathrm{f}, 2}$ for MM-TiSO anode, where the closed and open symbols indicate anodic and cathodic branch, respectively. 
activity should originate from the outer membrane cytochromes. ${ }^{44}$ Both anodes showed a major redox system with the formal potential $\left(E_{\mathrm{f}, 1}\right)$ of $-0.374 \mathrm{~V}$. In comparison, the MM-TisO anode also demonstrated another redox system with the formal potential of $-0.168 \mathrm{~V}$ versus an $E_{\mathrm{f}, 2}$ of $-0.24 \mathrm{~V}$ for the CC anode. Both systems for the MM-TiSO anode were found to possess a fine structure, implying the existence of additional redox processes. None of the redox peaks could be detected in the sterile medium and all peaks remained when the medium was refreshed with non-acetate medium, which indicated that all redox signals were the result of biofilm-based redox components. In addition, both redox processes should contribute to the bioeletrocatalytic electron transfer and they might be related to outer membrane cytochromes of exoelectrogenic G. sulfurreducens, which are crucial for the electron transfer from electricigens to a solid anode acceptor, such as OmcB, OmcE and OmcS, as reported previously. ${ }^{45,46}$ Taking OmcB as an example, a typical potential of $-0.19 \mathrm{~V} v s$. SHE was reported, ${ }^{47}$ and such potential appeared most likely to represent the redox system $E_{\mathrm{f}, 1}(-0.374 \mathrm{~V} v s$. SCE $)$ from this study. The presence of a second involved species at a more positive potential was also reported in prior studies, indicating a parallel and similar membrane-associated species. Nevertheless, the EET-relevant components that they represent are still unknown. ${ }^{\mathbf{4 8 4 9}}$

To study the electron transfer kinetics of outer membranebased redox systems in the MM-TiSO anode, the redox peak potentials with respect to the scan rate were analyzed. As shown in Fig. 4c and d, at slow scan rates, the potential difference between the oxidation and reduction peaks of $E_{\mathrm{f}, 1}(0.137 \mathrm{~V})$ was smaller than that of $E_{\mathrm{f}, 2}(0.346 \mathrm{~V})$. The peak potentials tended to shift with the increase in scan rate, showing a more developed peak separation. When scan rates were higher than $0.2 \mathrm{~V} \mathrm{~s}^{-1}$ and $0.15 \mathrm{~V} \mathrm{~s}^{-1}$ for $E_{\mathrm{f}, 1}$ and $E_{\mathrm{f}, 2}$, respectively, the cathodic peak shifted rather faster than the anodic peak. Moreover, the peak heights were positively proportional to the scan rate $\left(R^{2}=\right.$ 0.998). Based on the Laviron model, the transfer coefficient $(\alpha)$ was calculated to be 0.28 and 0.48 for $E_{\mathrm{f}, 1}$ and $E_{\mathrm{f}, 2}$, whereas the corresponding heterogeneous electron transfer rate constant $\left(k_{\mathrm{s}}\right)$ was estimated to be 0.97 and 0.14 , respectively. ${ }^{50}$ To further analyze the dependence of peak current on scan rate, the logarithmic peak current $\left(\log i_{\mathrm{p}}\right)$ vs. $\operatorname{logarithmic}$ scan rate $(\log v)$ was plotted. As a result, the $\log i_{\mathrm{p}}$ was found to be linearly correlated $\left(R^{2}=0.999\right)$ with $\log v$, accounting for a correlationship of $i_{\mathrm{pa}} \propto v^{0.63}, i_{\mathrm{pc}} \propto v^{0.68}$ for $E_{\mathrm{f}, 1}$, and $i_{\mathrm{pa}} \propto v^{0.51}, i_{\mathrm{pc}} \propto v^{0.52}$ for $E_{\mathrm{f}, 2}$, as calculated from the slope of $\log i_{\mathrm{p}} v s$. $\log v$ (data not shown). These results suggested a diffusion control of these EET-relevant components. ${ }^{22}$ On the basis of these results, the MM-TiSO anode could facilitate the electron transfer at the anolyte-biofilm-anode interface, resulting in a more efficient biocurrent generation in the MFC.

Since the performance of the MFC was the result of both EET efficiency and the bacterial clogging on the anode, the SEM characterization was conducted to observe the formation of microbial biofilm during the MFC operation. Notably, the macroscopic pores have a fine structure even with an intensive layer of biofilm grown on it after a long-time operation (Fig. 5a). The macroporous structure of the 3D MM-TiSO could facilitate

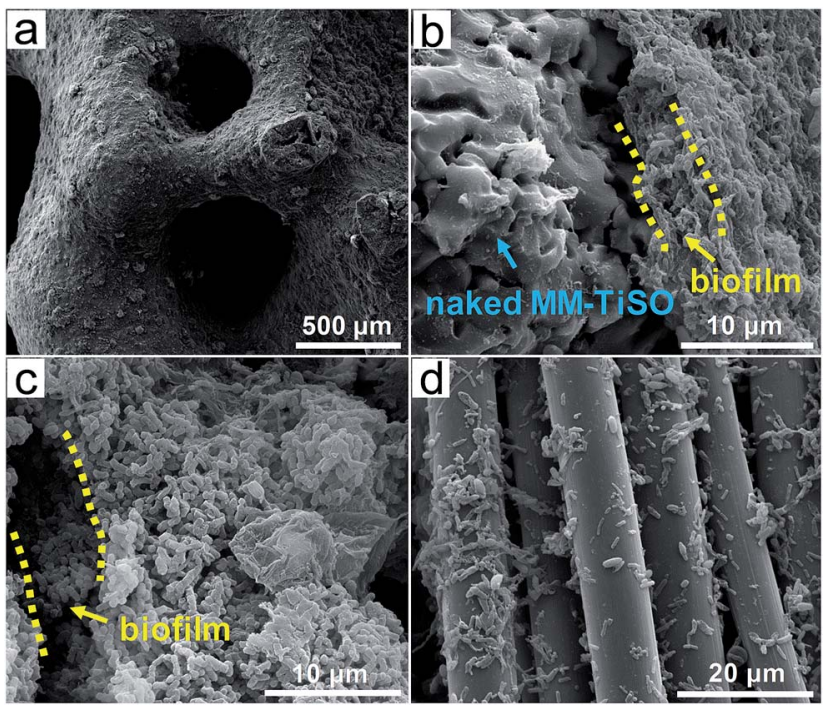

Fig. 5 SEM images of MM-TiSO (a-c) and CC (d) anodes after inoculation with mixed culture in MFCs.

the mass transfer of substrate to support the internal clogging of the bacterial biofilm. The high-density biofilm adhered almost over the entire multi-dimensional skeleton inside the deep structure of the 3D MM-TiSO material, and the thickness of the biofilm layer was about $10 \mu \mathrm{m}$ (Fig. 5b and c). There is no evident observation of an extracellular matrix of filament-like pili that would ensure connections from cell to cell or cell to electrode. The bacterial biofilm only attached onto some areas of the outermost surface of CC, but could not penetrate the inside space (Fig. 5d). Thus, the macroporous structure of MM-TiSO should be beneficial for recruiting bacteria onto the electrode. From these analyses, it can be inferred that the direct EET efficiency between redox-active proteins and the macroporous MM-TiSO can be enhanced by the increased surface area, improved bacterial adhesion, and the intimate contact.

In addition, one of the most outstanding properties of Magnéli-phase titanium suboxides is the superior chemical stability, which can be verified from the three following aspects. First, the titanium suboxides are reported to be able to survive up to 5000 cycles without a significant loss in the $\mathrm{O}_{2}$-saturated alkaline solution, and exhibit very little loss of electrochemically active surface area compared with carbon material under strong acidic conditions. ${ }^{28,51}$ Second, in our previous study, we carried out electrochemical accelerated life-span tests by recording potential versus time under extreme and harsh conditions (3.0 mol L ${ }^{-1} \mathrm{H}_{2} \mathrm{SO}_{4}$, current density of $1.0 \mathrm{~A} \mathrm{~cm}^{-2}, 30{ }^{\circ} \mathrm{C}$, Fig. $\left.\mathrm{S} 1 \dagger\right)$. The average lifetime of titanium suboxides was estimated to be 30 years, much longer than that of graphite material ( 7 years). ${ }^{52}$ Third, as revealed in the durability of MFCs tested herein (Fig. 3a), the titanium suboxides could sustain a stable voltage generation of $0.581 \pm 0.02 \mathrm{~V}$ during a long operational time (420 h), demonstrating much better stability than CC within the same tested conditions. In particular, the anode works under more moderate conditions in MFC than in electrochemical systems, such as neutral pH (otherwise the microbes would die), 
much lower current density $\left(<1 \mathrm{~mA} \mathrm{~cm}{ }^{-2}\right)$, and no concern for oxygen-induced corrosion (the electrochemically active microbes are anaerobic). Therefore, it should be reasonable to assume a much longer lifetime and expected durability for titanium suboxides in bioelectrochemical systems such as MFCs.

In conclusion, a novel 3D MM-TiSO with an open-cell macroporous structure was successfully prepared and studied as an anode material for MFCs. The inductive macropores provide an open space for bacteria colonization in the interior region and enhance the affinitive contact between the multilayered bacteria and the biocompatible macroporous TiSO monolith. The active component of MM-TiSO is speculated to stimulate the exoelectrogens to express more endogenous mediators for an enhanced mediated electron transfer rate. It is also thought to realize the direct electron transfer from various cytochrome proteins on the outer membrane, particularly OmcB. In addition, owing to its higher bacterial loading and EET efficiency, this 3D anode impressively outperforms the commonly used carbon cloth, and shows a boosted power output. Moreover, the monolith structure can protect the bacterial biofilm from being disrupted by the penetration of sharp features in practical application, offering a new strategy for the development of a high-performance MFC anode. Notably, a major attraction of the titanium suboxide material is that it can be produced from $\mathrm{TiO}_{2}$, a commodity chemical that is readily available across the world and environmentally friendly. This would make the electrode preparation and operation process more economically reliable and more environmentally friendly. Furthermore, titanium suboxides have a superior chemical stability similar to that of ceramics, which can be another advantage for MFC applications during long-term operations.

\section{Acknowledgements}

This research was financially supported by the National Natural Science Foundation of China (No. 51378143, 51678184), State Key Laboratory of Urban Water Resource and Environment (Grant No. 2015TS01), HIT Environment and Ecology Innovation Special Funds.

\section{Notes and references}

1 B. E. Logan, B. Hamelers, R. Rozendal, U. Schröder, J. Keller, S. Freguia, P. Aelterman, W. Verstraete and K. Rabaey, Environ. Sci. Technol., 2006, 40, 5181-5192.

2 U. Schröder, Phys. Chem. Chem. Phys., 2007, 9, 2619-2629.

3 G. Reguera, K. D. Mccarthy, T. Mehta, J. S. Nicoll, M. T. Tuominen and D. R. Lovley, Nature, 2005, 435, 10981101.

4 N. J. Kotloski and J. A. Gralnick, mBio, 2013, 4, 169-172.

5 Y. C. Yong, X. C. Dong, M. B. Chanpark, H. Song and P. Chen, ACS Nano, 2012, 6, 2394-2400.

6 S. Cheng, H. Liu and B. E. Logan, Environ. Sci. Technol., 2006, 40, 2426-2432.

7 J. Radjenovic and D. L. Sedlak, Environ. Sci. Technol., 2015, 49, 11292-11302.
8 J. R. Smith, F. C. Walsh and R. L. Clarke, J. Appl. Electrochem., 1998, 28, 1021-1033.

9 A. C. M. Padilha, J. M. Osorio-Guillén, A. R. Rocha and G. M. Dalpian, Phys. Rev. B: Condens. Matter Mater. Phys,, 2014, 90, 035213.

10 R. F. Bartholomew and D. R. Frankl, Phys. Rev., 1969, 187, 828-833.

11 P. Geng, J. Su, C. Miles, C. Comninellis and G. Chen, Electrochim. Acta, 2015, 153, 316-324.

12 J. Iniesta, P. A. Michaud and C. Comninellis, Electrochim. Acta, 2001, 46, 3573-3578.

13 J. E. Graves, D. Pletcher, R. L. Clarke and F. C. Walsh, J. Appl. Electrochem., 1991, 21, 848-857.

14 F. C. Walsh and R. G. A. Wills, Electrochim. Acta, 2010, 55, 6342-6351.

15 A. E. Stoyanova, E. D. Lefterova, V. I. Nikolova, P. T. Iliev, I. D. Dragieva and E. P. Slavcheva, Bulg. Chem. Commun., 2010, 42, 167-173.

16 A. M. Zaky and B. P. Chaplin, Environ. Sci. Technol., 2013, 47, 6554-6563.

17 A. M. Zaky and B. P. Chaplin, Environ. Sci. Technol., 2014, 48, 5857-5867.

18 D. Bejan, E. Guinea and N. J. Bunce, Electrochim. Acta, 2012, 69, 275-281.

19 S. T. Nguyen, J. M. Lee, Y. Yang and X. Wang, Ind. Eng. Chem. Res., 2012, 51, 817-820.

20 L. Guo, Y. Jing and B. P. Chaplin, Environ. Sci. Technol., 2016, 50, 155-166.

21 C. Tang, D. Zhou and Q. Zhang, Mater. Lett., 2012, 79, 42-44. 22 D. Portehault, V. Maneeratana, C. Candolfi, N. Oeschler, I. Veremchuk, Y. Grin, C. Sanchez and M. Antonietti, ACS Nano, 2011, 5, 9052-9061.

23 G. Hasegawa, T. Sato, K. Kanamori, K. Nakano, T. Yajima, Y. Kobayashi, H. Kageyama, T. Abe and K. Nakanishi, Chem. Mater., 2013, 25, 3504-3512.

24 B. Xu, Y. S. Hong, Y. Mohassab and Y. Lan, RSC Adv., 2016, 6, 79706-79722.

25 X. Tao, J. Wang, Z. Ying, Q. Cai, G. Zheng, Y. Gan, H. Huang, Y. Xia, C. Liang and W. Zhang, Nano Lett., 2014, 14, 52885294.

26 S. Harada, K. Tanaka and H. Inui, J. Appl. Phys., 2010, 108, 083703-083706.

27 U. Diebold and T. E. Madey, Surf. Sci. Spectra, 1996, 4, 227231.

28 X. Li, A. L. Zhu, W. Qu, H. Wang, R. Hui, L. Zhang and J. Zhang, Electrochim. Acta, 2010, 55, 5891-5898.

29 J. Cardenas and S. Sjöberg, Surf. Sci., 2003, 532, 1104-1108. 30 K. Fricke, F. Harnisch and U. Schröder, Energy Environ. Sci., 2008, 1, 144-147.

31 E. Marsili, D. B. Baron, I. D. Shikhare, D. Coursolle, J. A. Gralnick and D. R. Bond, Proc. Natl. Acad. Sci. U. S. A., 2008, 105, 3968-3973.

32 X. Zhu, M. D. Yates, M. C. Hatzell, R. H. Ananda, P. E. Saikaly and B. E. Logan, Environ. Sci. Technol., 2013, 48, 1352-1358.

33 K. P. Katuri, P. Kavanagh, S. Rengaraj and D. Leech, Chem. Commun., 2010, 46, 4758-4760. 
34 Y. Yuan, S. Zhou, Y. Liu and J. Tang, Environ. Sci. Technol., 2013, 47, 14525-14532.

35 A. Holewinski and S. Linic, J. Electrochem. Soc., 2012, 159, H864-H870.

36 S. Cheng and B. E. Logan, Electrochem. Commun., 2007, 9, 492-496.

37 S. Chen, Q. Liu, G. He, Y. Zhou, M. Hanif, X. Peng, S. Wang and H. Hou, J. Mater. Chem., 2012, 22, 18609-18613.

38 R. Song, C. E. Zhao, L. P. Jiang, E. S. Abdel-Halim, J. Zhang and J. J. Zhu, ACS Appl. Mater. Interfaces, 2016, 8, 1617016177.

39 M. Chen, Y. Zeng, Y. Zhao, M. Yu, F. Cheng, X. Lu and Y. Tong, J. Mater. Chem. A, 2016, 4, 6342-6349.

40 X. W. Liu, Y. X. Huang, X. F. Sun, G. P. Sheng, F. Zhao, S. G. Wang and H. Q. Yu, ACS Appl. Mater. Interfaces, 2014, 6, 351-418.

41 C. E. Zhao, J. Wu, S. Kjelleberg, J. S. C. Loo and Q. Zhang, Small, 2015, 11, 3440-3443.

42 X. B. Gong, S. J. You, Y. Yuan, J. N. Zhang, K. Sun and N. Q. Ren, ChemElectroChem, 2015, 2, 1307-1313.

43 C. Zhao, P. Gai, C. Liu, X. Wang, H. Xu, J. Zhang and J. J. Zhu, J. Mater. Chem. A, 2013, 1, 12587-12594.
44 H. J. Kim, H. S. Park, M. S. Hyun, I. S. Chang, M. Kim, B. H. Kim, H. S. Park, M. S. Hyun, I. S. Chang and M. Kim, Enzyme Microb. Technol., 2002, 30, 145-152.

45 L. Shi, S. M. Belchik, A. E. Plymale, S. Heald, A. C. Dohnalkova, K. Sybirna, H. Bottin, T. C. Squier, J. M. Zachara and J. K. Fredrickson, Appl. Environ. Microbiol., 2011, 77, 5584-5590.

46 K. A. Weber, L. A. Achenbach and J. D. Coates, Nat. Rev. Microbiol., 2006, 4, 752-764.

47 T. S. Magnuson, N. Isoyama, A. L. Hodgesmyerson, G. Davidson, M. J. Maroney, G. G. Geesey and D. R. Lovley, Biochem. J., 2001, 359, 147-152.

48 J. R. Lloyd, C. Leang, A. L. Hodges Myerson, M. V. Coppi, S. Cuifo, B. Methe, S. J. Sandler and D. R. Lovley, Biochem. J., 2003, 369, 153-161.

49 J. Wei, P. Liang, X. Cao and X. Huang, Environ. Sci. Technol., 2010, 44, 3187-3191.

50 E. Laviron, J. Electroanal. Chem., 1979, 100, 263-270.

51 C. Yao, F. Li, X. Li and D. Xia, J. Mater. Chem., 2012, 22, 16560-16565.

52 S. You, B. Liu, Y. Gao, Y. Wang, C. Y. Tang, Y. Huang and N. Ren, Electrochim. Acta, 2016, 214, 326-335. 